Available online at: http://openjournal.masda.ac.id/index.php/edumasda

Edu Masda Journal

ISSN (Print) 2597-4572 ISSN (Online) 2715-5269

\title{
INTERPRETASI KEPUASAN KONSUMEN TERHADAP PELAYANAN OBAT TANPA RESEP TERHADAP KEPUASAN KONSUMEN
}

\author{
Nurwulan Adi Ismaya ${ }^{*}$, Siti Novy Romlah ${ }^{2}$, Rofiqo Syafa'a Fatulloh ${ }^{3}$, Tri Okta \\ Ratnaningtyas ${ }^{4}$, Nur Hasanah ${ }^{5}$ \\ 1,3,4,5 STIKes Kharisma Persada, J1. Pajajaran No 1, Tangerang Selatan 15417, Indonesia \\ ${ }^{2}$ STIKes Widya Dharma Husada Tangerang, Jl. Pajajaran No 1, Tangerang Selatan 15417, Indonesia
}

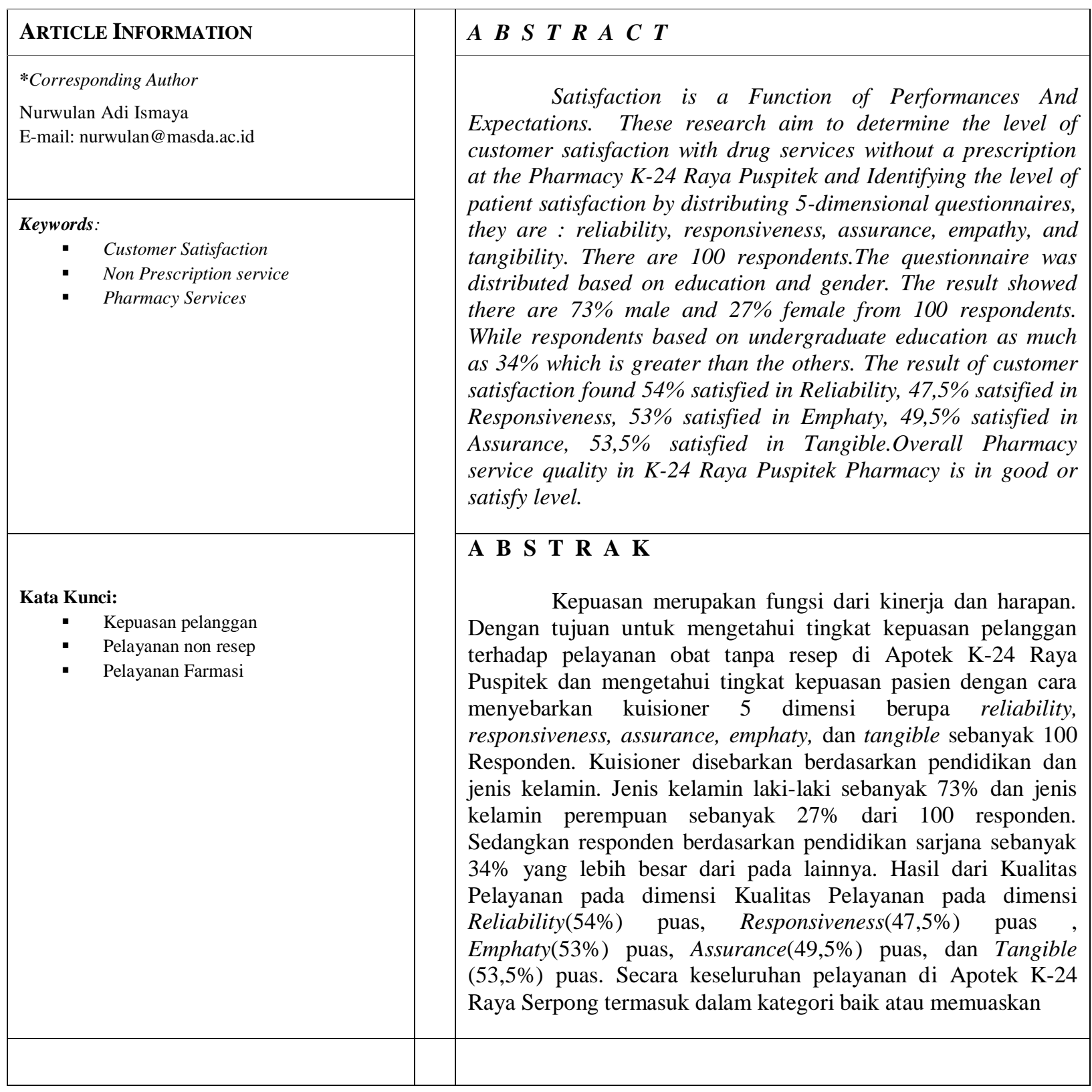




\section{PENDAHULUAN}

Apotek menjadi lini terdepan dari rantai pasok industri farmasi di Indonesia. Lebih dari $24 \%$ obat yang diproduksi oleh industri farmasi didistribusikan oleh Apotek (Sampurno, 2011). Setiap tahun jumlah Apotek semakin bertambah banyak, hal ini disebabkan karena semakin besarnya jumlah penduduk Indonesia dan berkembangnya masalah kesehatan yang semakin kompleks. Hingga saat ini sudah terdapat lebih dari 20.000 Apotek yang memiliki izin di Indonesia (Kementrian Kesehatan RI, 2018).

Dewasa ini pelayanan kefarmasian di Apotek dituntut untuk merubah orientasinya dari product atau drug oriented menjadi patient orienteed(Ihsan et. al. 2014). Pelayanan kefarmasian merupakan pelayanan kesehatan yang mempunyai peran penting dalam mewujudkan kesehatan bermutu dimana apoteker sebagai bagian dari tenaga kesehatan mempunyai tugas dan tanggung jawab dalam mewujudkan pelayanan kefarmasian yang berkualitas. Layanan kefarmasian selain menjadi tuntutan profesionalisme juga dapat dilihat sebagai faktor yang menarik minat konsumen terhadap pembelian obat di apotek. Pelayanan kefarmasian meliputi penampilan apotek, keramahan petugas, pelayanan informasi obat, ketersediaan obat, dan kecepatan pelayanan (Wibowo, 2017)

Kepuasan merupakan fungsi dari kinerja dan harapan. Jika kinerja dibawah harapan maka konsumen tidak puas, sebaliknya bila kinerja memenuhi harapan maka konsumen akan puas dan konsumen akan sangat puas jika kinerjanya melebihi harapan. Kepuasan konsumen berarti bahwa kinerja suatu barang atau jasa sekurang-kurangnya sama dengan apa yang diharapkan. Kepuasan pelanggan sangat erat kaitannya dengan kualitas pelayanan yang diberikan oleh apotek. Kualitas pelayananan kesehatan harus terus ditingkatkan untuk memberikan kepuasan kepada pelanggan yang membeli obat ke apotek(Kotler dan Keller, 2016). Untuk melakukan peningkatan kualitas pelayanan, perlu dilakukan survei kepada pelanggan tentang seberapa besar tingkat kepuasan mereka.

Kepuasan pasien menggunakan jasa apotek merupakan cerminan hasil dari mutu pelayanan kesehatan yang diberikan di apotek. Pelayanan tersebut dapat berupa interaksi dengan pelayanan medis, pasien, atau sistem pelayanan kesehatan secara keseluruhan baik itu dari administrasi, keuangan, serta tenaga kesehatan. Kepuasan menggunakan jasa apotek merupakan sikap dari konsumen dalam menentukan arah dan tujuan akhir dalam proses memahami pemakean obat secara 
tepat atau pembelian suatu produk obat (Alfianasari, 2010).

Penelitian yang dilakukan oleh Hendra (2017) tentang Gambaran Tingkat Kepuasan Pasien Terhadap Pelayanan Kefarmasian Di Apotek Kimia Farma 111 Banjarbaru menunjukkan rata-rata skor paling tinggi tingkat kepuasan pasien yaitu dimensi reliability dengan nilai 4,12, selanjutnya dimensi reliability dengan nilai 4,06, selanjutnya dimensi emphaty dengan nilai 3,89, lalu dimensi responsiveness dengan nilai 3,78 dan rata-rata skor paling rendah adalah dimensi tangible dengan nilai 3,42. Penelitian serupa juga dilakukan oleh Lina (2018) tentang Gambaran Tingkat Kepuasan Pasien Terhadap Pelayanan Kefarmasian Di Apotek Borneo Banjarmasin menunjukkan tingkat kepuasan pasien terhadap semua dimensi kepuasan secara keseluruhan yaitu sebanyak 50,87\% responden merasa sangat puas, $40,46 \%$ responden merasa puas, $8,67 \%$ responden merasa cukup puas dan $0 \%$ responden yang merasa kurang puas dan tidak puas.Penelitian lain yang dilakukan oleh Raising dan Erika (2019) tentang Analisis Kepuasan Pasien Terhadap Pelayanan Kefarmasian di Rumah Sakit dan Apotek menunjukkan hasil kuisioner yang telah dinilai skala persentase kepuasan responden, dimana pada dimensi kehandalan RS 75\% Apotek 78\%, Ketanggapan RS 68\% Apotek $76 \%$,
Jaminan RS $63 \%$ Apotek 72\%, Empati RS 74\% Apotek 69\%, Bukti langsung RS 69\% Apotek 61\%.

Masih rendahnya kepuasan pasien terhadap pelayanan farmasi di apotek, letak apotek K-24 Raya Puspitek di daerah padat penduduk, dan belum pernah dilakukan penelitian mengenai kepuasan pelayanan farmasi di Apotek K-24 Raya Puspitek membuat peneliti tertarik membuat penelitian yang berjudul Interpretasi Kepuasan Konsumen Terhadap Pelayanan Obat Tanpa Resep Terhadap Kepuasan Konsumen di Apotek K-24 Raya Puspitek Periode Februari April 2020.

\section{METODE}

Penelitian Kuantitatif dengan analisa data deskriptif, dilakukan di Apotek K-24 Raya Puspitek pada bulan Februari - April 2020. Populasi penelitian ini adalah seluruh pasien yang datang ke apotek dengan pembelian obat tanpa resep. Populasi dalam penelitian ini sebanyak 163.675 responden. Penetapan jumlah sampel dalam penelitian ini dihitung menggunakan rumus Slovin :yaitu sebagai berikut:

$$
\begin{gathered}
\mathrm{n}=\frac{n}{1+n \cdot e^{2}} \\
\mathrm{n}=\frac{163675}{1+163675 \times 0,1^{2}}
\end{gathered}
$$




$$
\mathrm{n}=\frac{163675}{1637,75}
$$

$\mathrm{n}=99,938$ dibulatkan $=100$

Jadi, sampel yang digunakan dalam penelitian ini sebesar 100 responden. Teknik sampling pada penelitian ini menggunakan Metode Accidential Sampling yang merupakan penentuan sampel bersarkan kebetulan, yaitu siapa yang kebetulan bertemu yang dipandang cocok dan sesuai dengan sumber data serta bersedia mengisi kuisioner. Data dikumpulkan dengan menggunakan kuisioner, kemudian dilakukan analisa secara deskriptif untuk melihat jumlah dan persentase dari tiap aspek kuisioner, data disajikan dalam bentuk tabel. Penelitian ini menggunakan kuisioner dan lembar analisa data sebagai instrumennya. Bahan penelitian ini adalah data rekam medik pasien.

HASIL

Hasil penelitian ini dianalisa berdasarkan poin - poin yang terkandung dalam tujuan khusus, bagan hasil ini terbagi menjadi dua topik, yaitu karakteristik responden yang meliputi usia dan jenis kelamin, serta 5 aspek dimensi kuisioner, yaitu : Kehandalan (Reliability), Daya Tanggap (Responsiveness), Perhatian (Emphaty), Jaminan (Assurance), Bukti Fisik (Tangible).

\section{Karakteristik Responden}

Responden dalam penelitian ini adalah karyawan yang memiliki karakteristik yang berbeda-beda yaitu berdasarkan usia, jenis kelamin dan pendidikan terakhir. Responden yang diambil adalah pelanggan Apotek K-24 Raya Puspitek sebanyak 100 responden. Setelah melakukan penyebaran kuesioner, maka dapat diperoleh gambaran atau karakteristik responden pelanggan Apotek K-24 Raya Puspitek.

Usia

Tabel 1. Data Responden Berdasarkan Usia

\begin{tabular}{ccc}
\hline Usia (tahun) & Frekuensi & Persentase \\
\hline $12-16$ & 3 & $3 \%$ \\
$17-25$ & 19 & $19 \%$ \\
$26-35$ & 31 & $31 \%$ \\
$36-45$ & 28 & $28 \%$ \\
$46-55$ & 12 & $12 \%$ \\
$56-65$ & 5 & $5 \%$ \\
$>65$ & 2 & $2 \%$ \\
Total & 100 & $100 \%$ \\
\hline
\end{tabular}

Sumber : Data Primer, 2020 
Berdasarkan data diatas dapat diketahui bahwa responden yang memiliki rata-rata tertinggi adalah yang berusia 26-35 tahun dengan jumlah 31 responden atau $31 \%$ dan yang memiliki rata-rata terendah yaitu yang berusia $>65$ tahun dengan jumlah 2 responden atau $2 \%$ dimana pengelompokan usia berdasarkan Depkes

RI (2009).

\section{Jenis Kelamin}

Tabel 2. Data Responden Berdasarkan Jenis Kelamin

\begin{tabular}{ccc}
\hline Jenis Kelamin & Frekuensi & Persentase \\
\hline Laki-laki & 73 & $73 \%$ \\
Perempuan & 27 & $27 \%$ \\
Total & 100 & $100 \%$
\end{tabular}

Sumber Data : Data Primer 2020

Berdasarkan data diatas dapat memiliki rata-rata terendah adalah responden diketahui bahwa responden lebih dari perempuan yang berjumlah 27 responden atau setengahnya yaitu $73 \%$ berjenis kelamin laki$27 \%$.

laki dengan jumlah 73 responden, dan yang

\section{Hasil Kuisioner 5 Dimensi Kualitas Pelayanan}

Jawaban responden dalam penelitian ini adalah jawaban yang berbeda-beda yaitu Sangat Puas, Puas, ragu-ragu, Tidak Puas, dan Sangat Tidak Puas.Jawaban responden yang diambil adalah jawaban dari pelanggan Apotek

\section{Aspek Kehandalan (Reliability)}

K-24 Raya Puspitek sebanyak 100 responden. Setelah melakukan penyebaran kuesioner, maka diperoleh gambaran jawaban responden pelanggan Apotek K-24 Raya Puspitek.

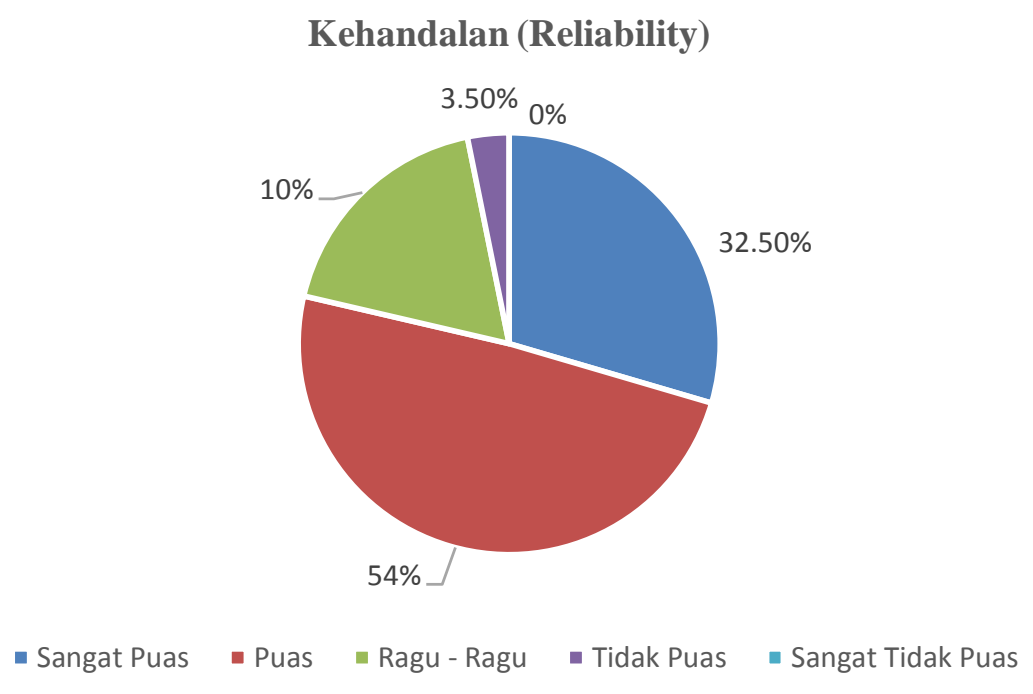

Gambar 1. Hasil Jawaban Responden terhadap Aspek Kehandalan (Reliability) 
Hasil kuisoner dalam aspek Kehandalan (Reliability)sebagian besar responden menjawab Puas sebesar 54\% kemudian sangat puas $32,5 \%$ sedangkan yang menjawab ragu-

Daya Tangkap (Responsiveness) ragu sebesar $10 \%$, tidak puas sebesar $3,5 \%$, dan responden yang menjawab sangat tidak puas sebesar $0 \%$.

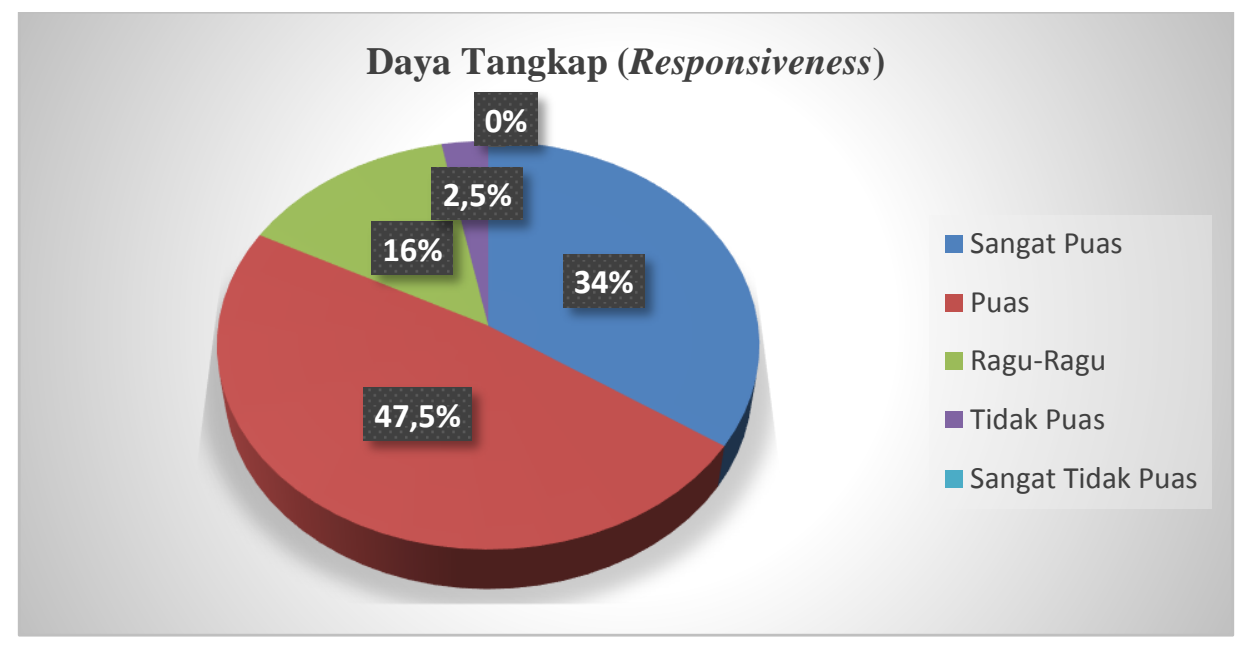

Gambar 2. Hasil Jawaban Responden terhadap Aspek Daya Tangkap (Responsiveness)

Hasil kuisoner dalam aspek Daya Tanggap (Responsiveness)sebagian besar responden menjawab puas sebesar $47,5 \%$ kemudian sangat puas $34 \%$ sedangkan yang menjawab Aspek Perhatian (Empathy) ragu-ragu sebesar 16\%, tidak Puas sebesar $2,5 \%$ dan responden yang menjawab sangat tidak puas sebesar $0 \%$.

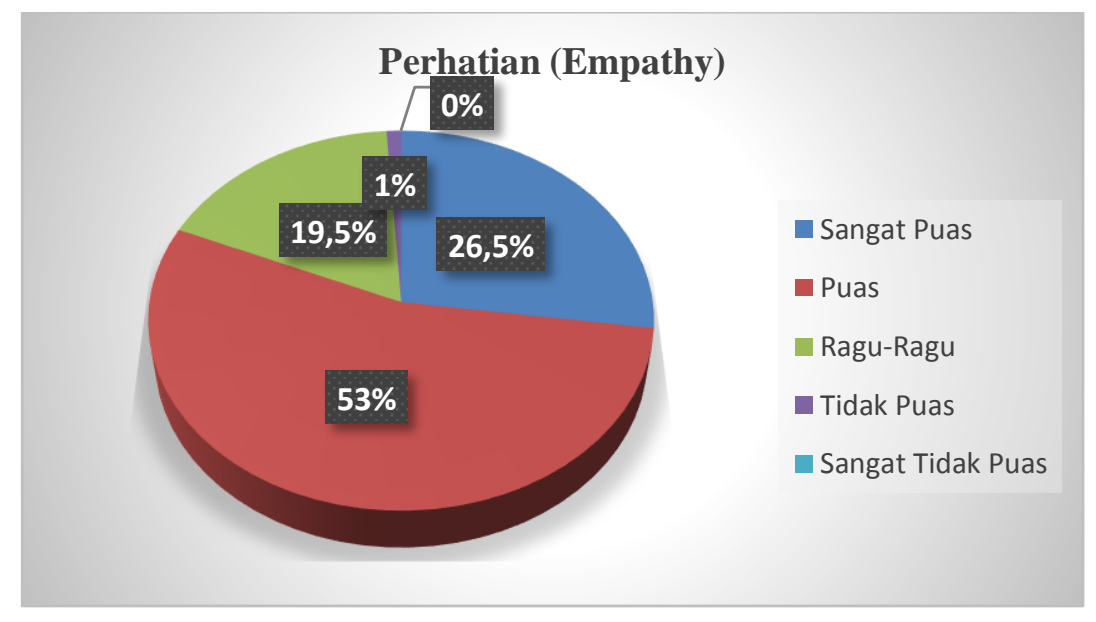

Gambar 3. Hasil Jawaban Responden terhadap Aspek Perhatian (Empathy)

Hasil kuisioner dalam aspek Perhatian (Emphaty)sebagian besar responden menjawab puas sebesar $53 \%$ kemudian sangat puas $26,5 \%$ sedangkan yang menjawab ragu - ragu sebanyak $19,5 \%$, 
tidak puas sebesar $1 \%$ dan responden yang menjawab sangat tidak puas sebesar $0 \%$.

\section{Aspek Jaminan (Assurance)}

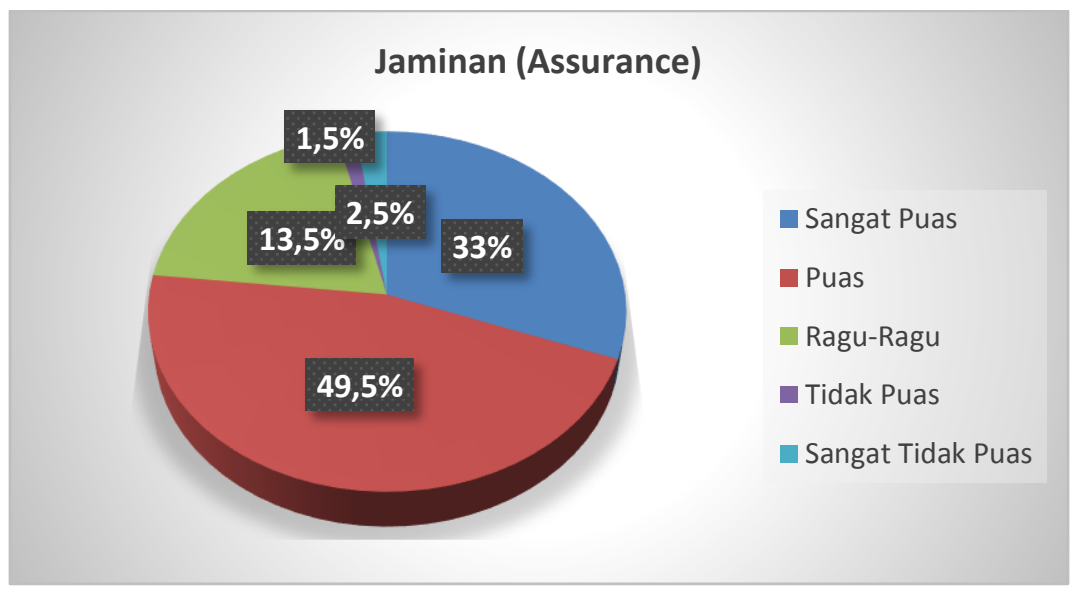

Gambar 4. Hasil Jawaban Responden terhadap Aspek Jaminan (Assurance)

Hasil kuisoner dalam aspek Jaminan (Assurance)sebagian besar responden menjawab puas sebesar 49,5\% kemudian sangat puas $33 \%$ sedangkan yang Aspek Bukti Fisik (Tangible)

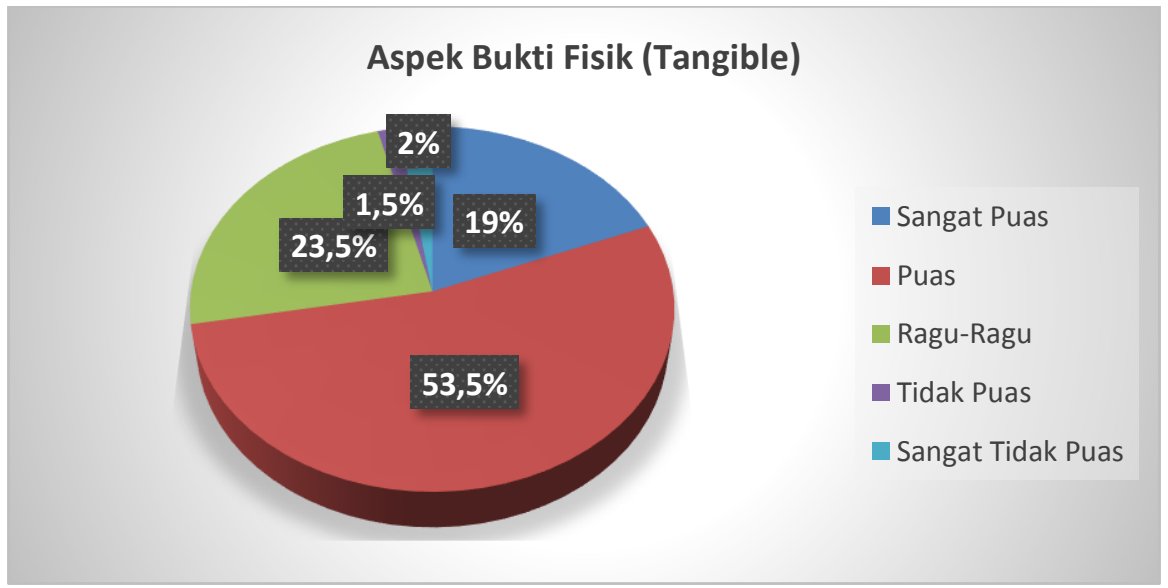

Gambar 5. Hasil Jawaban Responden terhadap Aspek Bukti Fisik (Tangible)

Hasil kuisoner dalam aspek Bukti Fisik (Tangible) sebagian besar responden menjawab puas sebesar $53,5 \%$ kemudian sangat puas $19 \%$ sedangkan yang menjawab ragu-ragu sebesar $13,5 \%$, tidak puas sebesar 1,5\% dan responden yang menjawab sangat tidak puas sebesar $2,5 \%$. 
Beberapa karakteristik yang diteliti meliputi karakteristik usia, jenis kelamin,dan pendidikan terakhir. Pada penelitian ini usia dikelompokkan menjadi 9 kelompok, usia remaja awal (6-12 tahun) berjumlah 3 orang (3\%), usia remaja akhir (17-25 tahun) berjumlah 19 orang (19\%), usia dewasa awal (26-35) berjumlah 31 orang (31\%), usia dewasa akhir (36-45 tahun) berjumlah 28 orang (28\%), usia lansia awal (46-55) berjumlah 12 orang (12\%), usia lansia akhir (56-65 tahun) berjumlah 5 orang (5\%), usia manula ( $>65$ tahunn) berjumlah 2 orang (2\%). Data tersebut menunjukan kelompok usia dewasa awal lebih dominan dibanding kelompok usia yang lain.

Jenis kelamin dikelompokkan menjadi dua kelompok yaitu laki-laki berjumlah 73 orang $(73 \%)$ dan perempuan 27 orang $(27 \%)$. Data tersebut menunjukakan laki-laki cenderung dominan dari perempuan. Pendidikan terakhir dikelompokkan menjadi 5 kelompok yaitu SD (0\%), SMP (15\%), SMA (25\%), Diploma (26\%), Sarjana (34\%). Data tersebut menunjukan pendidikan terakhir responden sarjana lebih dominan dibandingkan kelompok lainnya. Noverda dkk (2017) pada penelitiannya mengungkapkan seseorang dengan tingkat pendidikan lebih tinggi cenderung menuntut atau mengkritik terhadap pelayanan yang diterimanya jika memang menurutnya kurang puas. Sedangkan seseorang dengan tingkat pendidikan yang rendah cenderung lebih banyak menerima karena tidak tahu apa yang dibutuhkannya.

$$
\text { Pengukuran tingkat kepuasan }
$$
konsumen pada penelitian ini berdasarkan dimensi kepuasan yaitu kepuasan konsumen terhadap kualitas pelayanan obat tanpa resep di apotek K-24 Raya Puspitek. Hasil gambaran tingkat kepuasan yang didapat berdasarkan jawaban kuisoner yang diisi oleh konsumen apotek K-24 Raya Puspitek pada tabel 7 dari 100 responden dengan jawaban responden terbanyak terdapat pada kriteria puas $51,40 \%$ dan sangat puas $29 \%$ dengan pernyataan dalam kuisoner, sehingga dapat disimpulkan kualitas pelayan obat tanpa resep berbanding lurus dengan kepuasan konsumen dimana $80,4 \%$ konsumen merasa puas dengan pelayan farmasi obat tanpa resep di apotek K24 Raya Puspitek dan kualitas pelayan kefarmasian obat tanpa resep di apotek tersebuttermasuk dalam kategori sangat baiik.

Hasil penelitian menunjukan bahwa kepuasan konsumen terhadap kualitas pelayanan obat tanpa resep di apotek K-24 Raya Puspitek dalam aspek Reliability (54\%)

puas,Responsiveness $(47,5 \%)$,

Emphaty(53\%), Assurance(49,5\%),

Tangible (53,5\%). Hasil tersebut 
menunjukkan aspek Reliability, Responsiveness dan Assurancedalam kualitas pelayanan sudah sangat baik dan aspek emphaty dan Tangible masuk dalam kategori baik.

Tingkat kepuasan pada dimensi reliability sebagian besar responden menjawab Puas sebesar 54\% kemudian sangat puas $32,5 \%$ sedangkan yang menjawab ragu-ragu sebesar 10\%, tidak puas sebesar 3,5\%, dan responden yang menjawab sangat tidak puas sebesar $0 \%$. sehingga dapat disimpulkan kualitas pelayanan obat tanpa resep di apotek K-24 raya puspitek pada dimensi tersebut termasuk dalam kategori baik. Berdasarkan Peraturan Menteri Kesehatan Republik Indonesia Nomor 73 Tahun 2016 tentang Standar Pelayanan Kefarmasian di Apotek, apotek harus menjamin ketersediaan sediaan farmasi dan sumber daya manusia yang memberikan pelayanan kefarmasian dengan baik.

Dimensi

Responsiveness ditunjukkan sebagai kemampuan apotek untuk membantu pelanggan dan memberikan jasa cepat. Tingkat kepuasan pada dimensi Responsiveness sebagian besar responden menjawab puas sebesar $47,5 \%$ kemudian sangat puas $34 \%$ sedangkan yang menjawab ragu-ragu sebesar $16 \%$, tidak Puas sebesar 2,5\% dan responden yang menjawab sangat tidak puas sebesar 0\%. Data tersebut menyatakann $47,5 \%$ responden merasa puas atas dimensi Responsiveness sehingga dapat disimpulkan kualitas pelayanan obat tanpa resep di apotek K24 raya puspitek pada dimensi tersebut termasuk dalam kategori baik. Berdasarkan Peraturan Menteri Kesehatan Republik Indonesia Nomor 73 Tahun 2016 tentang Standar Pelayanan Kefarmasian di Apotek, tenaga kefarmasian mampu melakukan komunikasi dengan pasien atau keluarga pasien

Dimensi Emphaty yang dinilai pada dimensi ini adalah perhatian pribadi yang diberikan petugas apotek kepada konsumen/pasien. Sebagian besar responden menjawab puas sebesar 53\% kemudian sangat puas $26,5 \%$ sedangkan yang menjawab ragu - ragu sebanyak 19,5\%, tidak puas sebesar $1 \%$ dan responden yang menjawab sangat tidak puas sebesar 0\%.dapat disimpulkan kualitas pelayanan obat tanpa resep di apotek K24 raya puspitek pada dimensi tersebut termasuk dalam kategori baik. Berdasarkan Peraturan Pemerintah Nomor 51 Tahun 2009 tentang Pekerjaan Kefarmasian bahwa Tenaga Teknis Kefarmasian memberikan perlakuan sama dengan tidak membedakan suku, bangsa, agama, status sosial dan ras.

Dimensi Assurance, yang dinilai pada dimensi ini adalah jaminan terhadap pelayanan yang diberikan oleh apotek 
sebagai pemberi jasa untuk menimbulkan kepercayaan dan keyakinan. Sebagian besar responden menjawab puas sebesar $49,5 \%$ kemudian sangat puas $33 \%$ sedangkan yang menjawab ragu-ragu sebesar $13,5 \%$, tidak puas sebesar $1,5 \%$ dan responden yang menjawab sangat tidak puas sebesar 2,5\%. Kualitas pelayanan mempengaruhi kepuasan pasien, apabila kualitas pelayan baik maka kepuasan pasien akan tinggi. Data tersebut menyatakann $49,5 \%$ responden merasa puas atas dimensi Assurance mengenai Penampilan dan pengetahuan petugas Apotek meyakinkan sehingga dapat disimpulkan kualitas pelayanan obat tanpa resep di apotek K24 raya puspitek pada dimensi tersebut termasuk dalam kategori baik. Berdasarkan Peraturan Menteri Kesehatan Republik Indonesia Nomor 73 Tahun 2016 tentang Standar Pelayanan Kefarmasian di Apotek, tenaga kefarmasian harus memberikan informasi dan edukasi penggunaan obat yang baik kepada pasien atau keluarga pasien, sehingga obat yang diberikan sesuai dan obat terjamin kualitasnya.

Dimensi Tangible merupakan hal penunjang dasar dari sebuah pelayanan. Hal yang dinilai pada dimensi ini adalah bukti fisik dari suatu apotek. sebagian besar responden menjawab puas sebesar $53,5 \%$ kemudian sangat puas $19 \%$ sedangkan yang menjawab ragu-ragu sebesar $23,5 \%$ tidak puas sebesar $1,5 \%$ dan responden yang menjawab sangat tidak puas sebesar 2,5\% sehingga dapat disimpulkan kualitas pelayanan obat tanpa resep di apotek K24 raya puspitek pada dimensi tersebut termasuk dalam kategori baik. Ketersediaan fasilitas yang berkualitas dan terpelihara dengan baik maka konsumen/pasien lebih cenderung memilih pelayanan yang baik tersebut dibanding pelayanan yang memiliki sarana atau fasilitas yang lengkap tapi tidak terpelihara (Dewi dan Arta, 2014). Berdasarkan Peraturan Menteri Kesehatan Republik Indonesia Nomor 73 Tahun 2016 tentang Standar Pelayanan Kefarmasian di Apotek, sebaiknya pada sarana kefarmasian di Apotek memiliki fasilitas ruang yang memadai dalam hal kualitas dan kuantitas agar dapat menunjang fungsi dan proses pelayanan kefarmasian.

Penelitian serupa dilakukan oleh Ismail (2018) dimana dari data yang diperoleh menunjukan sebagian besar pasien menyatakan puas 34 orang (94\%) dan 2 orang menyatakan tidak puas $(6 \%)$. Hasil penelitian tersebut menyimpulkan karakteristik pasien tidak menentukan tingkat kepuasan dalam pelayanan kefarmasian di apotek wilayah Samata serta kualitas pelayanan kefarmasian berbanding lurus dengan kepuasan pasien atas pelayanan kefarmasian. Penelitian lain yang dilakukan oleh Novaryatiin dkk 
(2017) berdasarkan hasil penelitian, diketahui tingkat kepuasan pasien dengan rata-rata persentase interpretasi skor sebesar $68 \%$ yang artinya masuk dalam kategori puas. Penelitian serpa juga dilakukan oleh Akhmad (2019) dimana untuk mendapatkan gambaran kepuasan konsumen terhadap pelayanan apotek yang diukur berdasarkan dimensi tangible (penampilan apotek : sarana fisik, perlengkapan apotek, penampilan petugas apotek), dimensi reliability (kecepatan pelayanan apotek), dimensi responsiveness (keramahan petugas apotek), dimensi assurance (ketersediaan/kelengkapan obat di apotek), dan dimensi empathy (Pemberian informasi obat oleh petugas apotek). Jika dibandingkan dengan penelitian-penelitian sebelumnya, kepuasan pasienn terhadap pelayan kefarmasian di Apotek K24 Raya Puspitek masih tergolong dalam kategori baik

\section{KESIMPULAN}

Karakteristik Responden berdasarkan usia menunjukkan kelompok usia dewasa awal lebih dominan dibanding kelompokusia yang lain yaitu sebesar $31 \%$ dari total keseluruhan responden, berdasarkan jenis kelamin menunjukkan jenis kelamin laki-laki (73\%) lebih dominan dari pada perempuan. Kualitas Pelayanan pada dimensi Reliability(54\%) puas, Responsiveness $(47,5 \%)$ puas ,
Emphaty(53\%) puas, Assurance (49,5\%) puas, dan Tangible $(53,5 \%)$ puas.

\section{DAFTAR PUSTAKA}

Augusty, Ferdinand. 2016. Metode Penelitian Manajemen: Pedoman Penelitian untuk skripsi, Tesis dan Disertai Ilmu Manajemen. Semarang: Universitas Diponegoro.

Bahem, Nureeyah. 2017. Analisis Tingkat Kepuasaan Konsumen Terhadap Kualitas Pelayanan Obat Tanpa Resep di Apotek Nur Farma. Malang: UIN Maulana Malik Ibrahim Malang.

Departemen Kesehatan Republik Indonesia. 2016. Peraturan Menteri Kesehatan No 73 tahun 2016 tentang Permenkes Nomor 73 Tahun 2016 tentang Standar Pelayanan Kefarmasian di Apotek. Jakarta : Kementrian Kesehatan Republik Indonesia.

Fayol, Henry. 2014. Manajemen Public Relations. Jakarta: PT Elex Media. Follet, Mary Parker. 2013. Visionary Leadership and Strategic Management. MCB University Press. Women in Management Review Vol 14. No 7.

Ghozali, Imam. 2012. Aplkasi Analisis Multivariate dengan Program IBM 
SPSS 22. Semarang: Badan

Penerbit - $\quad$ Universitas

Diponegoro.

Irawan, Handi. 2012. 10 Prinsip Kepuasan

Pelanggan. Jakarta: PT Elex

Media Komputindo.

Kotler dan Amstrong. 2014."PrinsipprinsipPemasaran". EdisiKedua

Belas. Jilid Satu. Jakarta: Erlangga.

Hendra

Ary

Primadi,

Hendra (2017) Gambaran Tingkat

Kepuasan Pasien Terhadap

Pelayanan Kefarmasian Di Apotek

Kimia

Farma

111

Banjarbaru.http://www.akfar-

isfibjm.ac.id/. Karya Tulis Ilmiah

(KTI), Akademi Farmasi ISFI

Banjarmasin

Lina Elfiana Novita Zulfi,

Lina (2018) Gambaran Tingkat

Kepuasan Pasien Terhadap

Pelayanan Kefarmasian Di Apotek

Borneo

Banjarmasin.http://www.akfar-

isfibjm.ac.id/. Karya Tulis Ilmiah

(KTI), Akademi Farmasi ISFI

Banjarmasin.

Lovelock, Christopher dan Jochen Writz.

2011. Service Marketing. New

Jersey USA: Pearson.

Lupiyoadi, Rambat. 2013. Manajemen

Pemasaran Jasa. Jakarta: Salemba

Empat.
Schiffman, Leon G. And Leslie L. Kanuk. 2011. Consumer Behavior. Fifth Edition.New York: Prentice-Hall Inc.

Sugiyono. 2014. Metode Penelitian Pendidikan Pendekatan

Kuantitatif, kualitatif, dan R\&D. Bandung: Alfabeta.

Supranto J.2011. Statistik Teori dan Aplikasi.Jakarta: Erlangga.

Tjiptono, Fandy dan Gregorius Chandra. 2014. Pemasaran Strategik. Yogyakarta: ANDI.

Usfa, Junita Azimatul. 2017. Pengaruh Kualitas Pelayanan Pembelian Obat dan Pemilihan Lokasi Terhadap Minat Beli Konsumen Dalam Perspektif Ekonomi Islam (Studi Pada Konsumen Apotek Arroz Farma 24 Pringsewu). Lampung: UIN Raden Intan Lampung.

Yulia, Prima Roza. 2016. Kepuasan Konsumen Terhadap Pelayanan Apotek dan Tingkat Pengetahuan Konsumen Mengenai Standar Pelayanan Kefarmasiaan Yang Berlaku (Studi Kasus di Kota Depok). Bogor: Institut Pertanian Bogor.

Yuniar, Y. dan Handayani, R.S. 2016, Kepuasan Pasien Peserta Program JaminanKesehatan Nasional Terhadap Pelayanan Kefarmasian 
di Apotek, Jurnal Kefarmasian

Indonesia, 6(1): 39-48. 